University of Texas at El Paso

\title{
DigitalCommons@UTEP
}

Open Access Theses \& Dissertations

2013-01-01

\section{Effect Of Hafnium-Incorporation On The Microstructure And Dielectric Properties Of Cobalt Ferrite Ceramics}

Stephen Josiah Wells

University of Texas at El Paso, sjwells@miners.utep.edu

Follow this and additional works at: https://digitalcommons.utep.edu/open_etd

Part of the Electrical and Electronics Commons, Materials Science and Engineering Commons, Mechanical Engineering Commons, and the Mechanics of Materials Commons

\section{Recommended Citation}

Wells, Stephen Josiah, "Effect Of Hafnium-Incorporation On The Microstructure And Dielectric Properties Of Cobalt Ferrite Ceramics" (2013). Open Access Theses \& Dissertations. 1757.

https://digitalcommons.utep.edu/open_etd/1757 


\title{
EFFECT OF HAFNIUM-INCORPORATION ON THE MICROSTRUCTURE AND DIELECTRIC PROPERTIES OF COBALT FERRITE CERAMICS
}

\section{STEPHEN JOSIAH WELLS}

Department of Mechanical Engineering

\section{APPROVED:}

\author{
Chintalapalle Ramana, Ph.D., Chair
}

Yirong Lin, Ph.D.

Norman Love, Ph.D.

Bill Tseng, Ph.D.

Benjamin C. Flores, Ph.D.

Dean of the Graduate School 
Copyright (C)

by

Stephen Wells

2013 


\section{Dedication}

To my family and friends who have supported me so much. 


\title{
EFFECT OF HAFNIUM-INCORPORATION ON THE MICROSTRUCTURE AND DIELECTRIC PROPERTIES OF COBALT FERRITE CERAMICS
}

by

STEPHEN JOSIAH WELLS, B.S.M.E.

\author{
THESIS \\ Presented to the Faculty of the GraduateSchool of \\ The University of Texas at El Paso \\ in Partial Fulfillment \\ of the Requirements \\ for the Degree of
}

MASTER OF SCIENCE

Department of Mechanical Engineering

THE UNIVERSITY OF TEXAS AT EL PASO

August 2013 


\section{Acknowledgements}

I would like to thank God for sticking with me though all of this, even when I walked away from Him. I'd like to thank my family and friends for their support, my advisor, Dr. C. V. Ramana, and everyone in our research group for their support and patience. 


\begin{abstract}
The effect of hafnium ion $\left(\mathrm{Hf}^{4+}\right)$ incorporation in cobalt ferrite (CFO) was studied. Samples of Hf substituted CFO ceramic $\left(\mathrm{CoFe}_{2-\mathrm{x}} \mathrm{Hf}_{\mathrm{x}} \mathrm{O}_{4}\right)$, were synthesized in the laboratory with hafnium concentrations ranging from $x=0.000$ to $x=0.200$. X-ray diffraction scans show that the Hafnium $C F O$ crystalizes in the inverse spinel phase. Inclusion of hafnium causes lattice expansion, increasing the lattice parameter from $8.374 \AA$ for pure $\mathrm{CoFe}_{2} \mathrm{O}_{4}$ to $8.391 \AA$ for the highest concentration of hafnium tested $(\mathrm{x}=0.020)$. The dielectric properties of $\mathrm{CFO}$ are greatly enhanced by inclusion of hafnium. The enhancement is due to the distortion on the lattice from the larger Hf-ions substituting the smaller Feions. Frequency variation of the dielectric properties is well modeled by the modified Debye function, which takes into account multiple ions contributing to relaxation.
\end{abstract}




\section{Table of Contents}

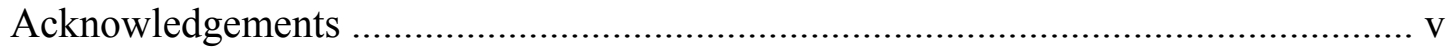

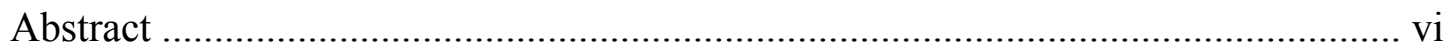

List of Tables ....................................................................................... viii

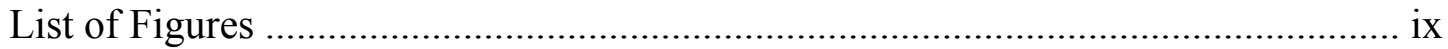

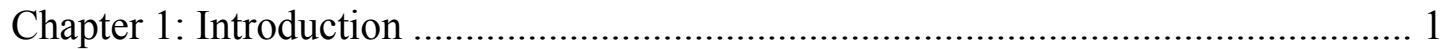

1.1 Cobalt Ferrite - Structure, Chemistry and Properties ........................... 1

1.2 Motivation and Significance of the Present Work ................................. 3

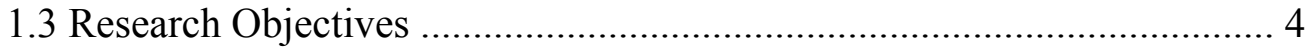

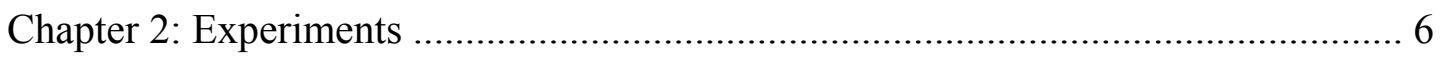

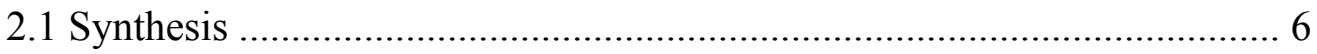

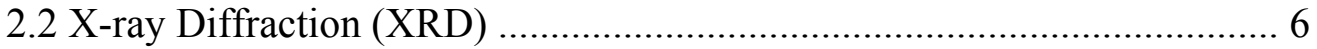

2.3 Scanning Electron Microscopy (SEM) ............................................... 9

2.4 Energy Dispersive X-ray Spectrometry (EDS) .................................. 11

2.5 Dielectric Property Measurements ................................................... 12

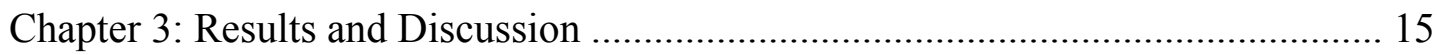

3.1 Crystal Structure and Phase Identification ......................................... 15

3.2 Morphology and Composition ….................................................... 20

3.3 Dielectric Properties ........................................................................ 22

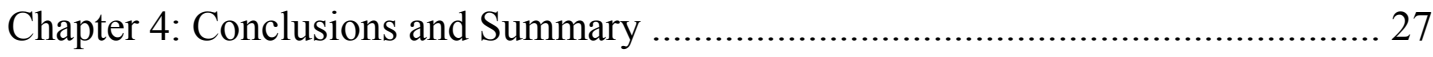

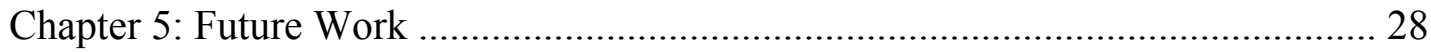

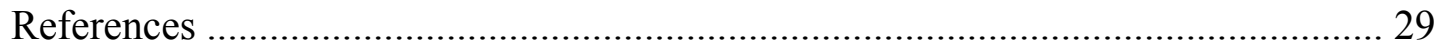

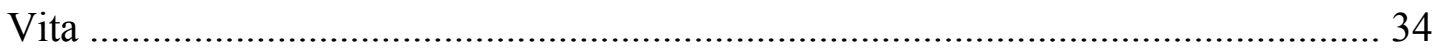




\section{List of Tables}

Table 1 Comparison of refined values of bond angle and bond length in pure $\mathrm{CoFe}_{2} \mathrm{O}_{4}$ and

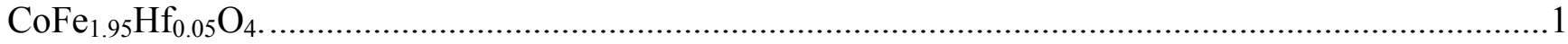




\section{List of Figures}

Fig.1.1 (a) Spinel unit cell structure, Fig. (b) Octahedral interstice (B site: 32 per unit cell, 16 occupied), and Fig. (c) Tetrahedral interstice (A site: 64 per unit cell, 8 occupied). In figure (a), the ionic positions are the same in octants sharing only one edge and different in octants sharing a face. Each octant contains 4 Oxygen ions. In (a) ionic positions in only two adjacent octants are shown, where the octant on the left contains octahedral and the one on the right contains tetrahedral sites. All ions are positioned on body diagonals of the octants and the octant on the right contains a tetrahedral site at the octant center. [17] .

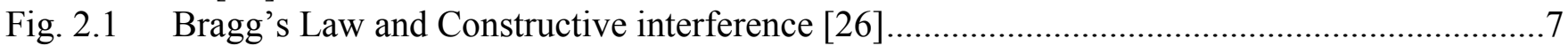

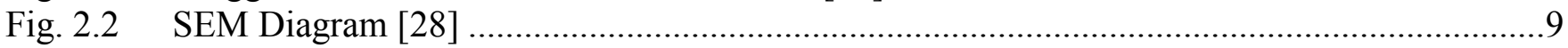

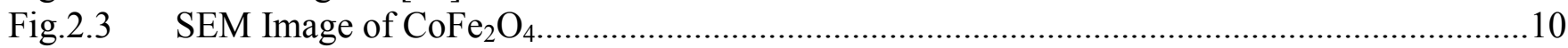

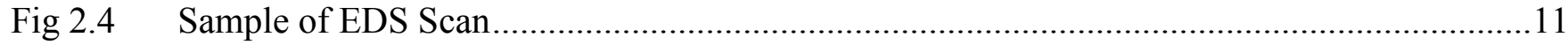

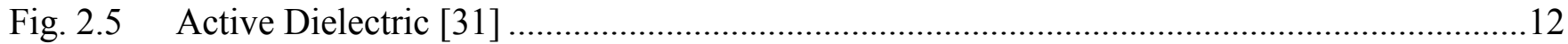

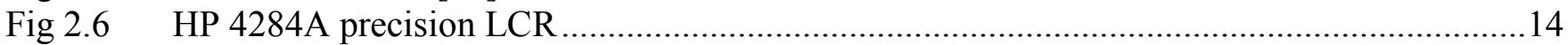

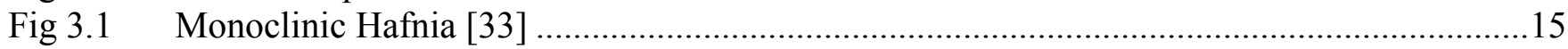

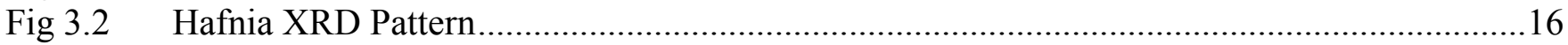

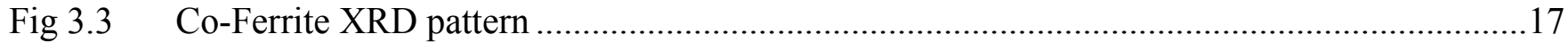

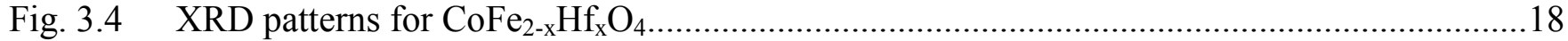

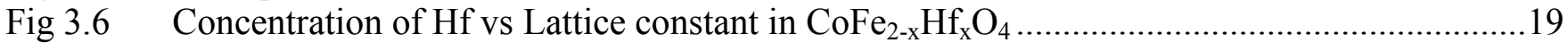

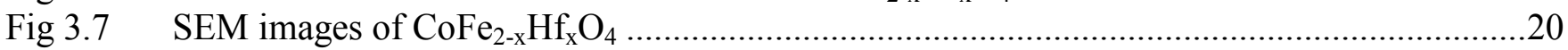

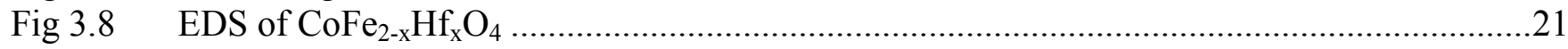

Fig 3.9 Real Portion of Dielectric Constant vs Frequency ………..................................................22

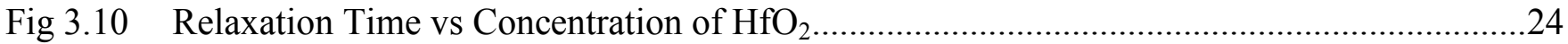

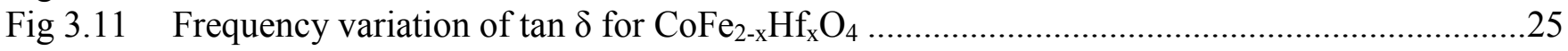




\section{Chapter 1: Introduction}

Ferrite materials have received significant attention in recent years due to their wide range of applications in the fields of electronics, optoelectronics, magnetics, magneto-electronics, and electrochemical science and technology [1-16]. Nickel (Ni) ferrites, in particular, have been studied extensively due to their remarkable properties such as high saturation magnetization, large permeability at high frequency, and remarkably high electrical resistivity [6-8]. Due to their low eddy current losses, there exists no other material with such wide ranging value to electronic applications in terms of power generation, conditioning, and conversion [10]. These properties also make them unique for application in microwave devices which require strong coupling to electromagnetic signals [11]. Unlike most materials, they possess both high permeability and moderate permittivity at frequencies from dc to the millimeter [11]. The focus of the present thesis work is the cobalt ferrite $\left(\mathrm{CoFe}_{2} \mathrm{O}_{4}\right)$ based composite materials. Therefore, a brief introduction to cobalt ferrite is presented below.

\subsection{Cobalt Ferrite - Structure, Chemistry and Properties}

Cobalt ferrite $\left(\mathrm{CoFe}_{2} \mathrm{O}_{4}\right)$ (abbreviated as $\mathrm{CFO}$ ) was one of the parent materials used in this study. This is a hard ferrite with good magnetic anisotropy and magnetostriction. It is being considered for use as a high density magnetic storage device because of its moderate saturation magnetization $\left(\mathrm{M}_{\mathrm{S}}\right)$, high coercive force $\left(\mathrm{H}_{\mathrm{C}}\right)$, and good chemical stability and mechanical hardness [7].

The structural and electronic feature is of the compound gives it its excellent magnetic and electron properties. $\mathrm{CFO}$ has an inverse spinel structure (Figure 1.1). A unit cell of CFO has a lattice

parameterof $8.39 \AA$, consists of eight formula units [8]. The $\mathrm{Fe}^{3+}$ ions in tetrahedral sites are aligned antiferromagnetically with respect to the $\mathrm{Fe}^{3+}$ ions in the octahedral sites giving superexchange interactions mediated by oxygen ions. This leaves the $\mathrm{Co}^{2+}$ ions to determine the saturation magnetism 
as $3 \mu \mathrm{B}$ per formula unit. Instead of this, the actual value from experiments is found as $4 \mu \mathrm{B}$. Several factors could contribute to the difference in the theoretical and actual values. The orbital motion of the electrons could have an effect. The $\mathrm{F}^{3+}$ dipoles might not be perfectly anti-parallel as assumed. Also, the Co ions might not be as evenly distributed as assumed by the calculations [9].

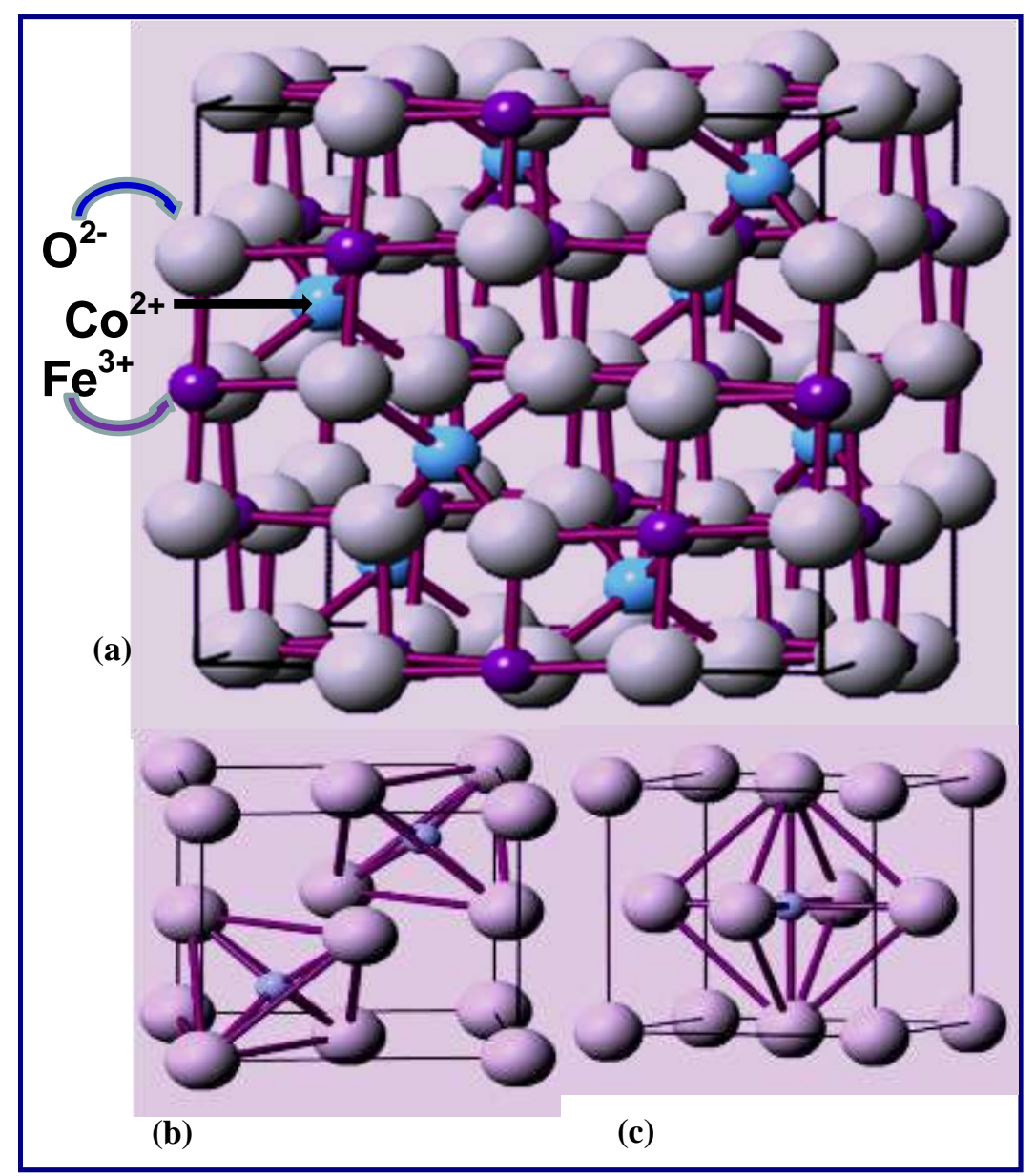

Fig.1.1 (a) Spinel unit cell structure, Fig. (b) Octahedral interstice (B site: 32 per unit cell, 16 occupied), and Fig. (c) Tetrahedral interstice (A site: 64 per unit cell, 8 occupied). In figure (a), the ionic positions are the same in octants sharing only one edge and different in octants sharing a face. Each octant contains 4 Oxygen ions. In (a) ionic positions in only two adjacent octants are shown, where the octant on the left contains octahedral and the one on the right contains tetrahedral sites. All ions are positioned on body diagonals of the octants and the octant on the right contains a tetrahedral site at the octant center. [17]

The microstructure significantly influences the magnetic and electronic properties of CFO. Homogeneity is an important factor, as is the presence of phases other than the primary phase. The other 
phases could be secondary or impurity phases. The size and shapes of the grains and crystallites has a strong effect as well. Uniformity is important for good magnetic and electrical properties in chemical composition as well as porosity, internal strain, microscopic grain structure, and phase relationships.

The following are the wide range of applications of CFO-based materials:

1. Spinel type cobalt ferrite is the only oxide material with large enough magnetostriction in normal operating conditions to work as a substitute at this time, and is a possible economical solution to the sensor and actuator technology based on magnetostriction. Low cost, good mechanical stability, better coupling coefficient, low thermal conductivity, high electrical resistance, and excellent in corrosion resistance all make CFO a good option for this technology [10].

2. CFO has large magneto-crystalline anisotropy with a reasonable magnetization value. As mentioned before, this gives it promise as a magnetic recording material [11].

3. Out of the different spinel ferrites, CFO has the most promise as an electrode for oxygen evolution from fused salts. Fused salt represents a difficult system, where most materials don't operate effectively. CFO has, however, shown itself to be a good stable anode.

4. CFO's inverse spinel structure is useful for studying the electro-magnetic effects of microstructure and lattice strain. Since the cations can be moved about the interstitial sites by various techniques, the microstructure can be changed, and the effects recorded.

5. The hard ferrite CFO has a relatively high coercivity, exchange bias, and moderate magnetization. When coupled with its high thermo and chemical stability, this gives a wide variety of uses to the compound in the electronic, computer and biomedical industries [15].

\subsection{Motivation and Significance of the Present Work}

Because of their wide variety of applications in modern technology, much study is underway to understand the properties of ferrites in great detail and learn how to custom tailor their properties for 
specific targeted applications. This means continued research into the magnetic, electric and dielectric properties of the spinel ferrite family of materials. CFO can be seen as one of the most promising members of this family, and deserves good focus from research. Also, CFO is a possible material for use in novel magnetostrictive smart materials [18].

It is also to be noted that the resistivity of the ferrites is high enough that eddy current losses are negligible in applications of inductance [19]. This has drawn attention away from the dielectric characteristics of spinel ferrites, but as their applicability at microwave frequencies is being demonstrated, the dielectric properties of these materials must also be examined. To this end, the current study is aimed examining the microstructure and dielectric properties of Hafnium oxide $\left(\mathrm{HfO}_{2}\right)$ incorporated into CFO. A detailed investigation of structure and dielectric properties of $\mathrm{CFO}-\mathrm{HfO}_{2}$ ceramics had been made and is presented in this thesis.

There are two primary reasons for choosing the subject of this investigation. The first is that there have been no previous studies on Hf incorporated CFO to the best of our knowledge. Because of this, much new enlightenment about the general patterns of ion substitution should begin to come to light over time from this research. In addition, Hf-based ceramic materials have many excellent properties such as high chemical/thermal stability and high dielectric constants along with other great electrical properties [20-24]. $\mathrm{HfO}_{2}$ is a good example as it has a wide band gap, high dielectric constant, and excellent chemical/thermal stability coupled with great mechanical properties. This gives it uses in fields of structural ceramics, electronics, magnetism, and optoelectronics [20-24]. $\mathrm{HfO}_{2}$ has even been considered for replacing $\mathrm{SiO}_{2}$ in many computer and nanoelectronic areas because of its chemical stability in contact with $\mathrm{SiO}_{2}$ and strong dielectric constant [22, 23]. For these reasons, $\mathrm{CoFe}_{2-\mathrm{x}} \mathrm{Hf}_{\mathrm{x}} \mathrm{O}_{4}$ ceramic materials show great promise for having good mechanical, electric and magnetic properties.

\subsection{RESEARCH OBJECTIVES}

The research objectives of this work are: 
1. Synthesis of $\mathrm{CFO}-\mathrm{HfO}_{2}$ ceramics with variable $\mathrm{Hf}$ content.

2. Understand the structural and chemical composition of the $\mathrm{CoFe}_{2-\mathrm{x}} \mathrm{Hf}_{\mathrm{x}} \mathrm{O}_{4}$ ferrites.

3. Evaluate the dielectric properties of $\mathrm{CFO}-\mathrm{HfO}_{2}$ ceramics as a function of composition, and frequency $(20 \mathrm{~Hz}-1 \mathrm{MHz})$.

4. Understand the mechanisms responsible for the dielectric behavior, dielectric relaxation properties, and loss factor associated with $\mathrm{CFO}-\mathrm{HfO}_{2}$ ceramics. 


\section{Chapter 2: Experiments}

\subsection{SYNTHESIS}

$\mathrm{CoFe}_{2-\mathrm{x}} \mathrm{Hf}_{\mathrm{x}} \mathrm{O}_{4}$ ceramics were synthesized using the conventional solid state chemical reaction method. $\mathrm{CoO}, \mathrm{Fe}_{2} \mathrm{O}_{3}$, and $\mathrm{HfO}_{2}$ powders (all with $99.99 \%$ purity) were used as the starting materials. The powders were ground with a mortar and pestle for an hour before being heated at $1200{ }^{0} \mathrm{C}$ for 12 hours in open air. The tablets were formed by pressing some of the powder into the correct shape, and then sintering the tablets at $1250{ }^{\circ} \mathrm{C}$ for another 12 hours. By varying the relative amounts of each base powder used, different concentrations of $\mathrm{x}=0.000,0.050,0.075,0.100,0.150$, and 0.200 were synthesized for both the powder samples and the tablets. These different specimens were used to study the properties of the Hf-oxide/Co ferrite composite.

\subsection{X-RAY DIFFRACTION (XRD)}

The structure of the ceramics synthesized was examined by the X-ray Diffraction (XRD). XRD is one of the best ways to determine the crystal structure of a material and can also give reading of the internal stress of the sample. The basic physical law behind this method is Bragg's Law, which has use in a wide number of fields [25]. Bragg's Law (Figure 2.1) relates to the scattering of waves hitting a crystal lattice.

$$
n \lambda=2 d \sin \theta
$$

Here, $\mathrm{n}$ is an integer, $\lambda$ is the wavelength of the wave striking the lattice, $\mathrm{d}$ is the distance between the crystal planes, and $\theta$ is the angle between the diffracted wave and the planes of the crystal. 


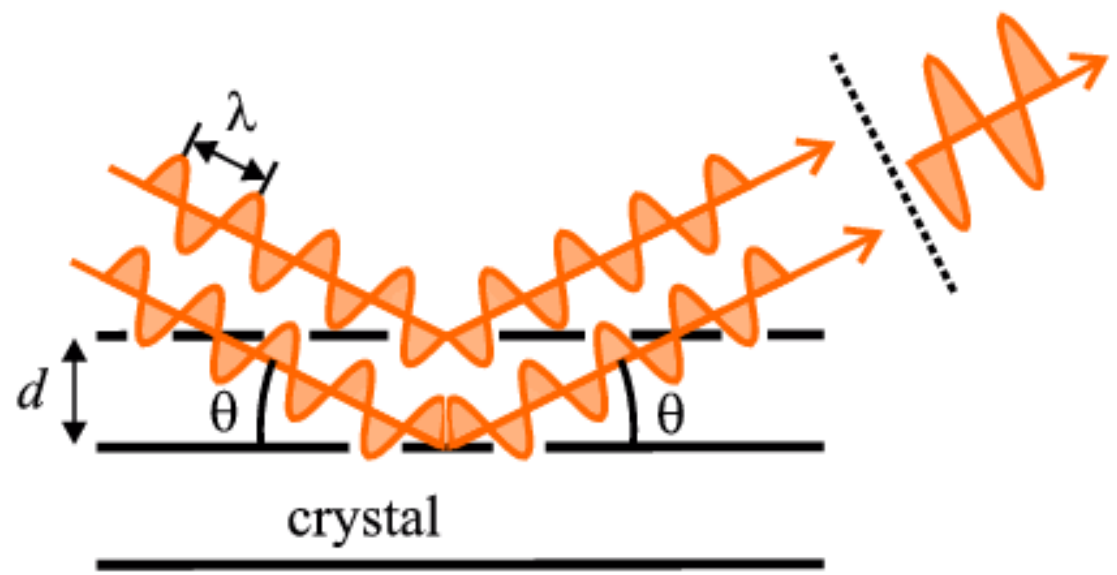

Fig. 2.1 Bragg's Law and Constructive interference [26]

Bragg's Law describes the conditions under which waves striking the crystal will be scattered inphase. Constructive interference occurs when the law's conditions are met, giving a measureable relation between the diffracted waves and the structure of the crystal. As waves that are in-phase with each other amplify each other's amplitudes, distinct patterns of diffraction angles occur, corresponding to the spacing between the planes struck by the waves [25]. This works when the waves striking the planes are of a wavelength similar to the spacing between the atomic layers [25]. When analyzing a single crystal, individual points on what is called an "Ewald sphere" can be measured from each instance of an X-ray peak. When a powder is analyzed, many different orientations of the crystal lattice are present in the sample, forming conical patterns called "Debye cones." The projections of these cones (Debye rings) are measured and the angles of diffraction are taken from an arch intersecting the Debye cones at a single point each [25].

Many structural aspects of a sample can be determined from the graph obtained in the test. The position of a peak corresponds to different d-spacing and crystal structures, whereas the intensity of the peak relates to crystal structure and the amount of a phase in the sample. The shape of a peak can tell about strain, grain size, and even the internal defects of the sample [25]. To analyze a sample of known 
chemical composition, the sample's phase can be identified by comparison against previous profiles in databases. Since the ratio of peak intensities for two phases varies linearly with the weight fraction of the two, it is easy to calculate the amounts of different phases present. Measuring the d-spacing and lattice parameters, and comparing them to known relations between the two for different primitive cells can tell the unit cell structure, since certain peak patterns are known to match certain primitive unit cells [25]. Since the d-spacing of symmetric cells repeats itself in different directions, the more symmetric the cell, the more peaks are repeated, and the fewer peaks are seen on the graph.

Crystallite size can be measured by examining the width of a peak. Specifically, a measure called full width at half maximum (FWHM), which refers to the measurement of width half way up the peak, can be used to calculate the crystallite size from the Scherrer equation.

$$
B(2 \theta)=\frac{K \lambda}{L \cos \theta}
$$

Here, $\mathrm{B}$ is the FWHM, $\lambda$ is the wavelength of the X-rays, $\theta$ is the diffraction angle of the reflection, $\mathrm{K}$ is a shape factor dependent on the shape of the crystals, and $\mathrm{L}$ is the volume average of crystal thickness in the direction normal to the reflecting planes [25]. This method assumes uniformity in the crystal's sizes and shapes.

When dealing with new materials or compounds and composites that have less known data, a method called Rietveld analysis is often used to analyze the data from a sample. Rietveld analysis is a very powerful tool that can tell most aspects of a sample's crystal structure, percentage of phase amounts and even grain sizes among other things. The analysis is performed by a computer program simulating XRD profiles for theoretical crystal structures, and fitting the actual data to those generated profiles. Since compounds usually have similar structures to their parent compounds, simulated structures and their profiles can be generated within range of the actual compound. The main goal of Rietveld is to minimalize the residual function from the calculated profile and the measured profile [25]. 
For the measurements used here, a Bruker D8 Discover X-ray diffractometer was used. The applied radiation was $\mathrm{Cu} \mathrm{K}_{\alpha}(\lambda=1.5406 \AA)$. The same $\mathrm{HfO}_{2}$ powder used to synthesize the compound was tested to get a reference of one parent compound to compare to the XRD patterns of the new material. The $\mathrm{CoFe}_{2-\mathrm{x}} \mathrm{Hf}_{\mathrm{x}} \mathrm{O}_{4}$ samples were tested for all concentrations of $\mathrm{Hf}$, and the data compiled and analyzed.

\subsection{Scanning Electron Microscopy (SEM)}

Since their inception in the 1950's, electron microscopes have become one of the most useful research tools in biology, physics, and material science [27]. Just as the human eye and normal microscopes focus light (photons) through lenses to detect images, SEM systems use electromagnets to focus an electron beam onto a sample, and create a detailed image by picking up the reflected electrons and X-rays given off by the beam's impact [27].

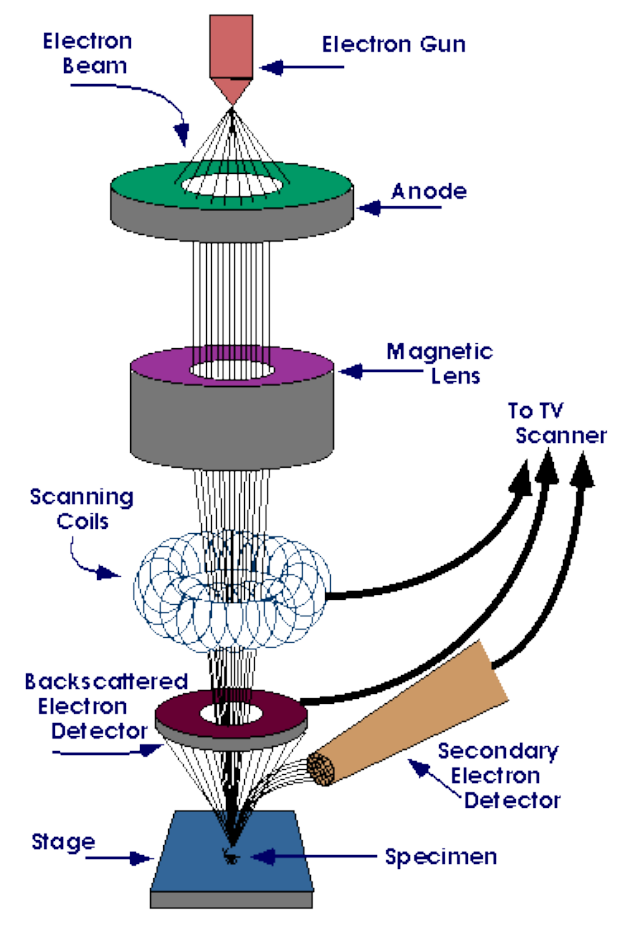

Fig. 2.2 SEM Diagram [28] 
The SEM works by firing an electron beam at a sample, and then detecting the backscattered electrons from the beam strike as well as the X-rays and translating them into a visual signal. An electromagnet is used to focus the beam to different levels of magnificationas seen in Figure 2.2. The sample is held in a vacuum when the test is performed, which limits the application of SEM to substances that will not outgas in a vacuum. Also, since a conducting path is needed for the electron beam, non-metallic substances are sometimes sputter coated in a thin layer of metal for the test [27].

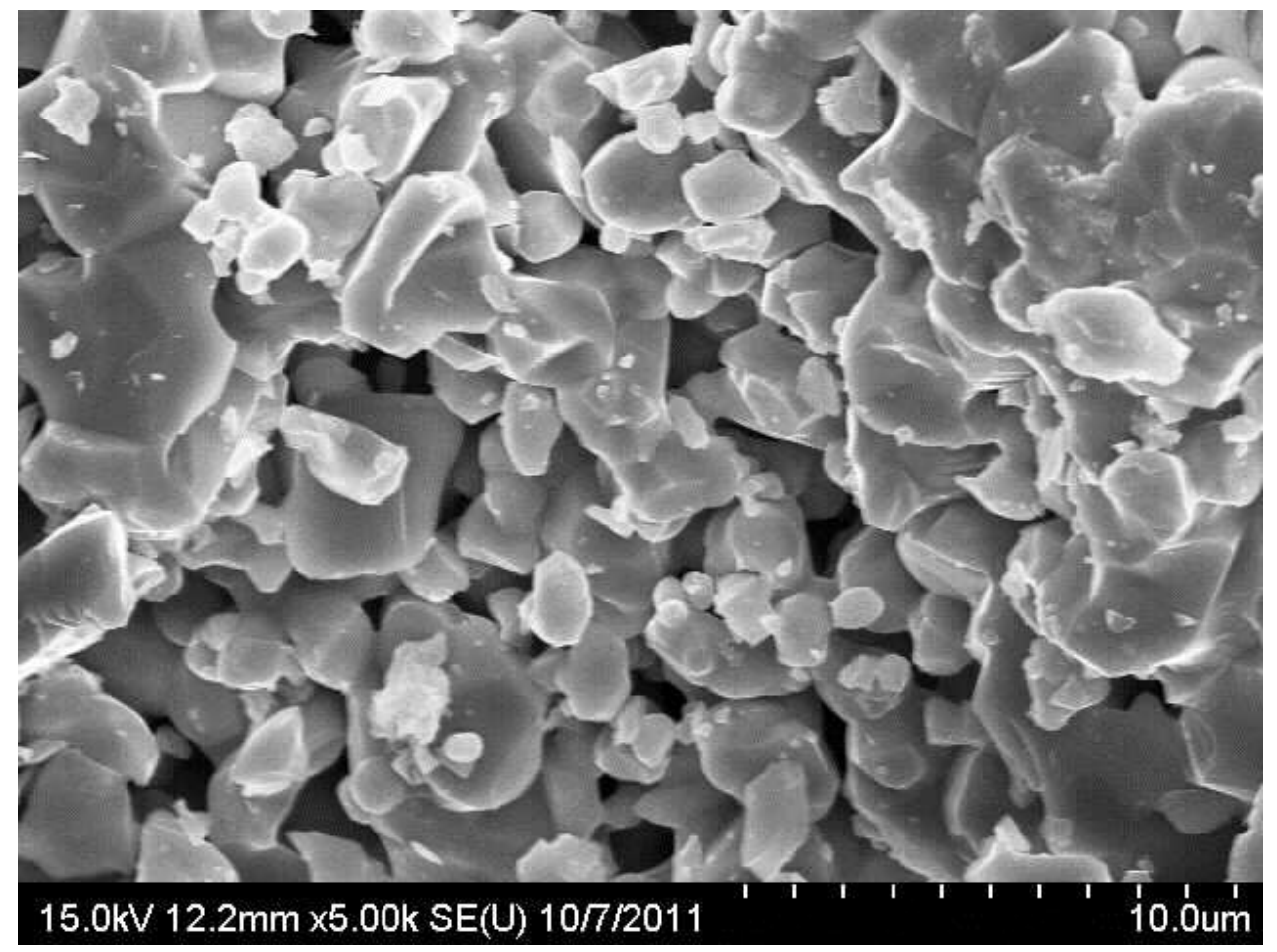

Fig.2.3 SEM Image of $\mathrm{CoFe}_{2} \mathrm{O}_{4}$

To perform the SEM scans for this study, $\mathrm{CoFe}_{2-\mathrm{x}} \mathrm{Hf}_{\mathrm{x}} \mathrm{O}_{4}$ powder was spread on a carbon tape, which was then attached to an Al target. The SEM machine used for the scans was a high resolution Hitachi S-4800 SEM. The electron beam was at $15 \mathrm{kV}$ and the secondary backscattered electrons were detected to form the images gathered. 


\subsection{ENERGY DISPERSIVE X-RAY SPECTROMETRY (EDS)}

Energy-dispersive X-ray spectroscopy or EDS (also called EDX or XEDS) is a technique for measuring the elemental content of a sample. EDS scanners are often part of SEM experimental setups. As mentioned earlier, when an electron beam strikes a sample, the sample emits X-rays. The scanner measures the energy and wavelength of the X-rays emitted by the sample, and interprets the data to determine the element that the X-ray came from. Different types of X-rays are produced depending on which shell the initial electron vacancy came from in the production of the X-rays therefore the shell $(\mathrm{K}$, $\mathrm{L}, \mathrm{M}$, etc.) is identified in the name of the $\mathrm{X}$-ray. For example, $\mathrm{Cu} \mathrm{K \alpha}$ came from a copper target, which had a hole in the $\mathrm{K}$ shell caused by the beam, and the $\alpha$ shows that the electron that fell to fill the hole came from the adjacent $\mathrm{L}$ shell (coming from the $\mathrm{M}$ shell that's above the $\mathrm{L}$ shell, would be $\mathrm{K} \beta$ ). From the name, one can also distinguish which electron in the shell was involved. This would be the difference between $\mathrm{K} \alpha 1$ and Ka2. In EDS this isn't taken into account, because the sensors don't distinguish between them, and just show a $\mathrm{K} \alpha$ peak that is the weighted average between the $\mathrm{K} \alpha 1$ and $\mathrm{K} \alpha 2$ [29].

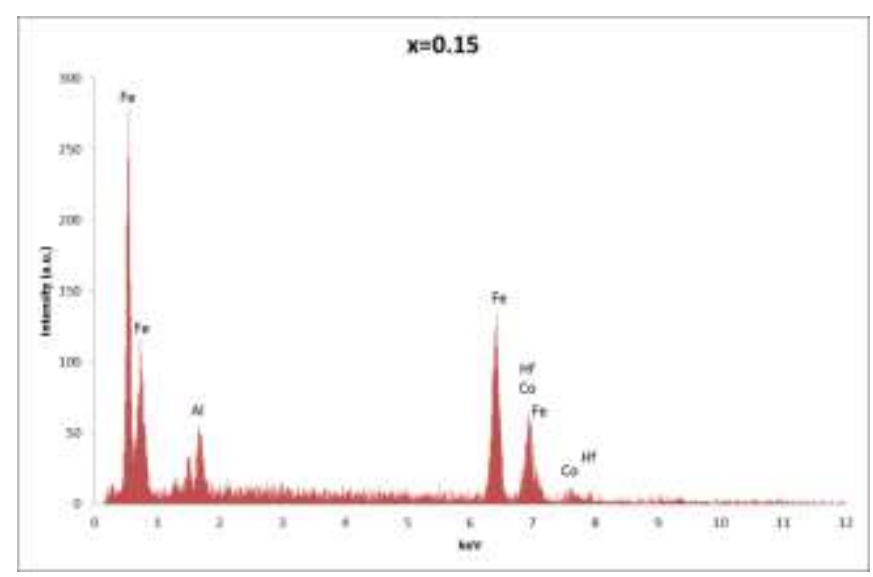

Fig 2.4 Sample of EDS Scan 
Another prominent use for EDS is to show the distribution of elements in a sample. By scanning over an area, the way in which the elements are distributed can be mapped [29]. For this study, EDS scans were taken for powder samples of all Hf concentrations. The same Hitachi S-4800 machine used for the SEM scans was used for the EDS scans.

\subsection{Dielectric Property Measurements}

The basic principal of dielectrics is polarizability. When exposed to an electric field, the molecules or ions in a substance line up to form many dipoles. Polar molecules already are dipoles, and simply line up with the electric field. Non-polar molecules become polarized if in a strong enough electric field (Figure 2.5). Even ions in a crystal lattice can shift slightly from their base positions to form dipoles aligned with the field. The stronger the dipoles formed by this, the higher the dielectric constant of the material. When a dielectric is placed in an active capacitor, the electric field of the capacitor creates aligned dipoles in the material, which in turn form their own electric field in material counter to the electric field of the capacitor. This gives a lower net electric field in the capacitor [30].

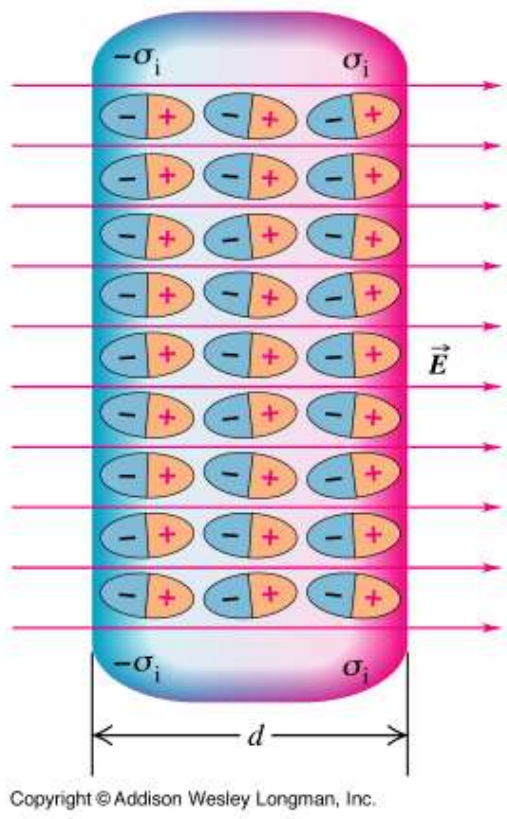

Fig. 2.5 Active Dielectric [31] 
The second of the two most important effects of the polarization of the dielectric, is the surface charges that form on the sides of the dielectric. These are opposite the surface charges on the capacitor surface that the dielectric touches. Since this gives a lower net charge on the capacitor than without the dielectric, the capacitor can hold more charge than without the dielectric for the same voltage. Because the capacitance is simply the charge a capacitance can hold per applied voltage, dielectrics increase the capacitance of a capacitor. The increase is proportional to the dielectric constant of the material [30].

$$
\begin{aligned}
& C=\frac{Q}{V} \\
& C=\varepsilon_{r} C_{0}
\end{aligned}
$$

Here, $\mathrm{C}$ is capacitance, $\mathrm{Q}$ is charge, $\mathrm{V}$ is applied voltage, $\varepsilon_{\mathrm{r}}$ is dielectric constant and $\mathrm{C}_{0}$ is original capacitance. In addition to finding the dielectric constant of the material, two other properties were measured: the relaxation time and the dielectric loss factor.

When a dielectric is removed from an electric field, there is delay in depolarization of the material. This is called the relaxation time. It is usually quite short, even $\mu \mathrm{s}$, but a few materials can have relaxation times in the thousands of years [30].

Dielectric loss factor is a relative measure of how much energy is lost to a dielectric in an AC circuit. Thermal agitation prevents the dipoles from keeping up with the changing electric field in an AC capacitor. This leads to energy losses in the dielectric described by the term $\tan \delta$ (the loss factor). This term is the ratio of the real to imaginary portion of $\varepsilon_{\mathrm{r}}[32]$.

$$
\begin{aligned}
& \tan \delta=\frac{\varepsilon_{r}^{\prime}}{\varepsilon_{r}^{\prime \prime}} \\
& W_{v o l}=\omega E^{2} \varepsilon_{0} \varepsilon_{r}^{\prime} \tan \delta
\end{aligned}
$$

Here, $\mathrm{W}_{\mathrm{vol}}$ is the power loss per volume for the dielectric, $\omega$ is the radian frequency, $\mathrm{E}$ is the electric field, and $\varepsilon_{\mathrm{r}}{ }^{\prime}$ and $\varepsilon_{\mathrm{r}}{ }^{\prime}$, are the real and imaginary parts of the dielectric constant [32]. 
For this project, the real portion of the dielectric constant, and the loss factor were measaured over a range of frequencies. The relaxation time was calculated for each concentration. Measurements were taken using an HP 4284A precision LCR meter at room temperature.

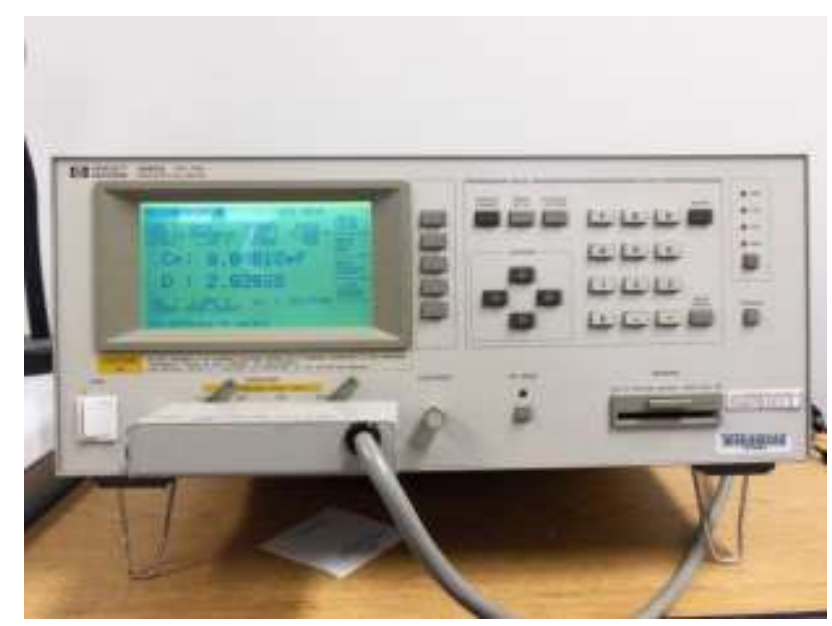

Fig 2.6 HP 4284A precision LCR 


\section{Chapter 3: Results and Discussion}

\subsection{Crystal Structure and Phase Identification}

The $\mathrm{HfO}_{2}$ powder XRD results indicated that the Hafnia powder used in the study has a monoclinic structure as shown in Figs 3.1 and 3.2. This is in keeping with the literature on the subject. Monoclinic unit cells have unequal sides, two $90^{\circ}$ angles, and one non- $90^{\circ}$ angle. Hafnia has $\mathrm{Hf}^{+}$ions in a face centered monoclinic cell, with $\mathrm{O}^{-2}$ ions in interstitial sites. Lattice parameters were measured as $a=5.1156 \AA, b=5.1722 \AA$ and $c=5.2948 \AA$. A highest peak of the (-111) plane happened at $2 \theta=28.356^{\circ}$, in keeping with literature for the crystal structure (JCPDS No. 74-1506).
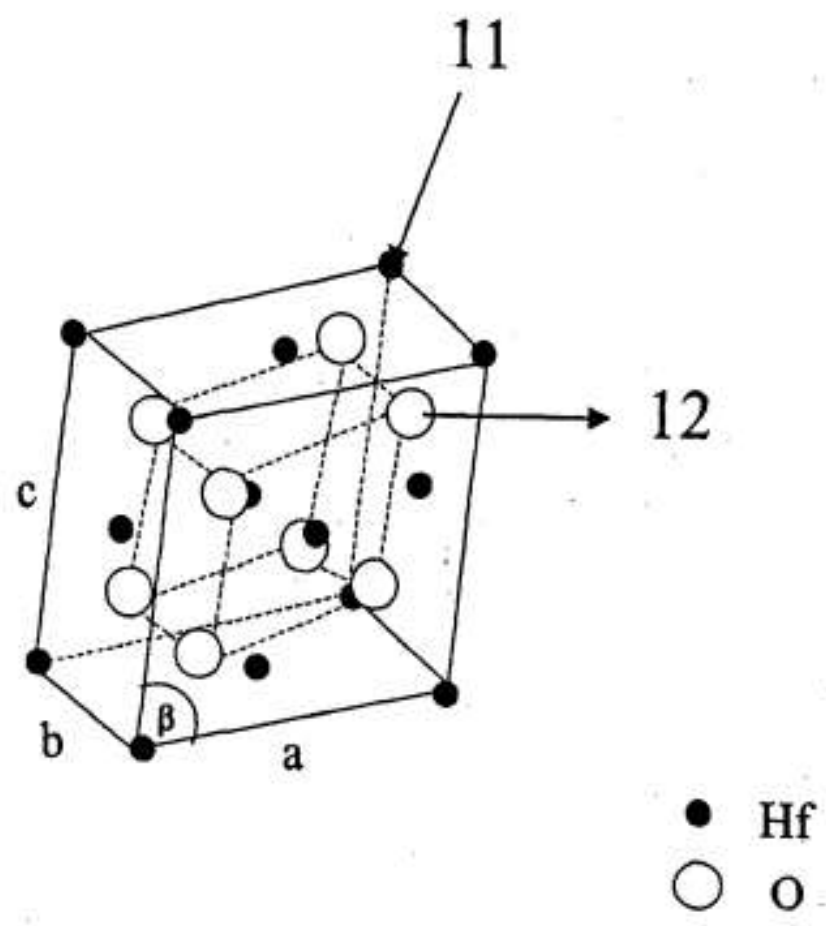

Fig 3.1 Monoclinic Hafnia [33] 


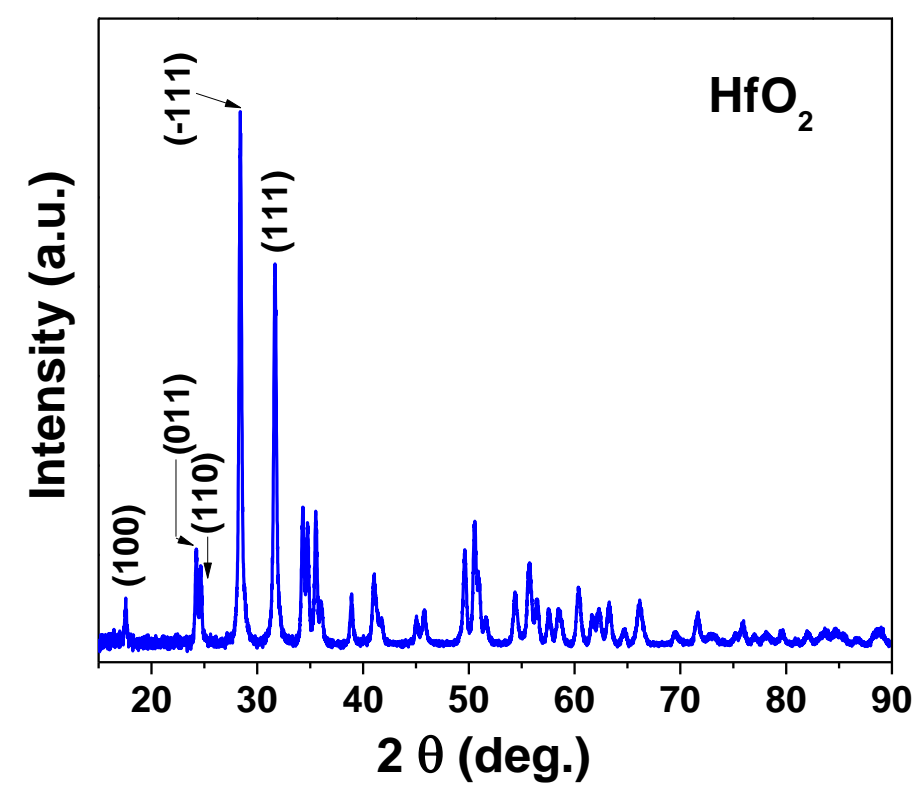

Fig 3.2 Hafnia XRD Pattern

Previous studies have shown an inverse spinel structure for Co-Ferrite. Figure 3.3 shows the XRD pattern of $\mathrm{CoFe}_{2} \mathrm{O}_{4}$ after Rietveld refinement using the GSAS program [34]. Shown in the figure are also the wrp (weighted refined parameter), and the $\chi^{2}$ (goodness of the fit). The Lattice constant for the structure was found in the referenced study to be $8.374 \AA$. Spinel structure is a common structure for substances of the chemical form $\mathrm{AB}_{2} \mathrm{O}_{4}$, where $\mathrm{A}$ and $\mathrm{B}$ represent transition metals $\mathrm{A}(\mathrm{II})$ and $\mathrm{B}(\mathrm{III})$. The oxygen forms a face centered cubic structure (close packed) and the transition metals occupy tetrahedral and octahedral interstitial sites respectively. $1 / 8$ of the tetrahedral sites are occupied and $1 / 2$ of the octahedral sites are occupied. In an inverse spinel structure, half of the B(III) ions swap places with the $\mathrm{A}(\mathrm{II})$ ions, such that the tetrahedral sites are occupied by $\mathrm{B}(\mathrm{III})$ and both $\mathrm{A}(\mathrm{II})$ and $\mathrm{B}(\mathrm{III})$ occupy the octahedral sites [35]. 


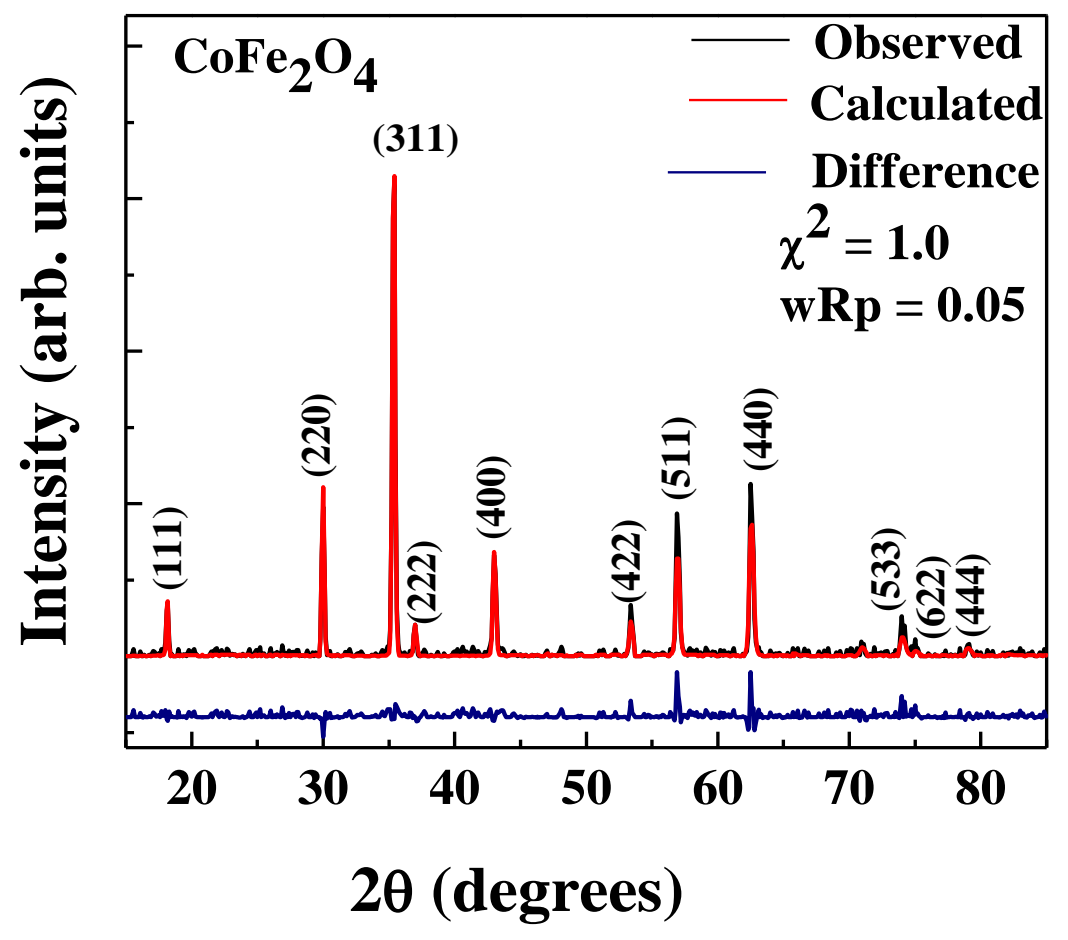

Fig 3.3 Co-Ferrite XRD pattern

The structure of the $\mathrm{Hf}$ incorporated $\mathrm{CoFe}_{2} \mathrm{O}_{4}$ is very interesting in its development with increasing $\mathrm{Hf}$ concentration. XRD patterns are shown in the figure below for the different concentrations. The composite is in the inverse spinel phase just as its parent $\mathrm{CoFe}_{2} \mathrm{O}_{4}$. As the $\mathrm{Hf}$ in $\mathrm{CoFe}_{2-\mathrm{x}} \mathrm{Hf}_{\mathrm{x}} \mathrm{O}_{4}$ ranges from $\mathrm{x}=0$ to $\mathrm{x}=0.2$, separate $\mathrm{HfO}_{2}$ phase forms at higher concentrations. 


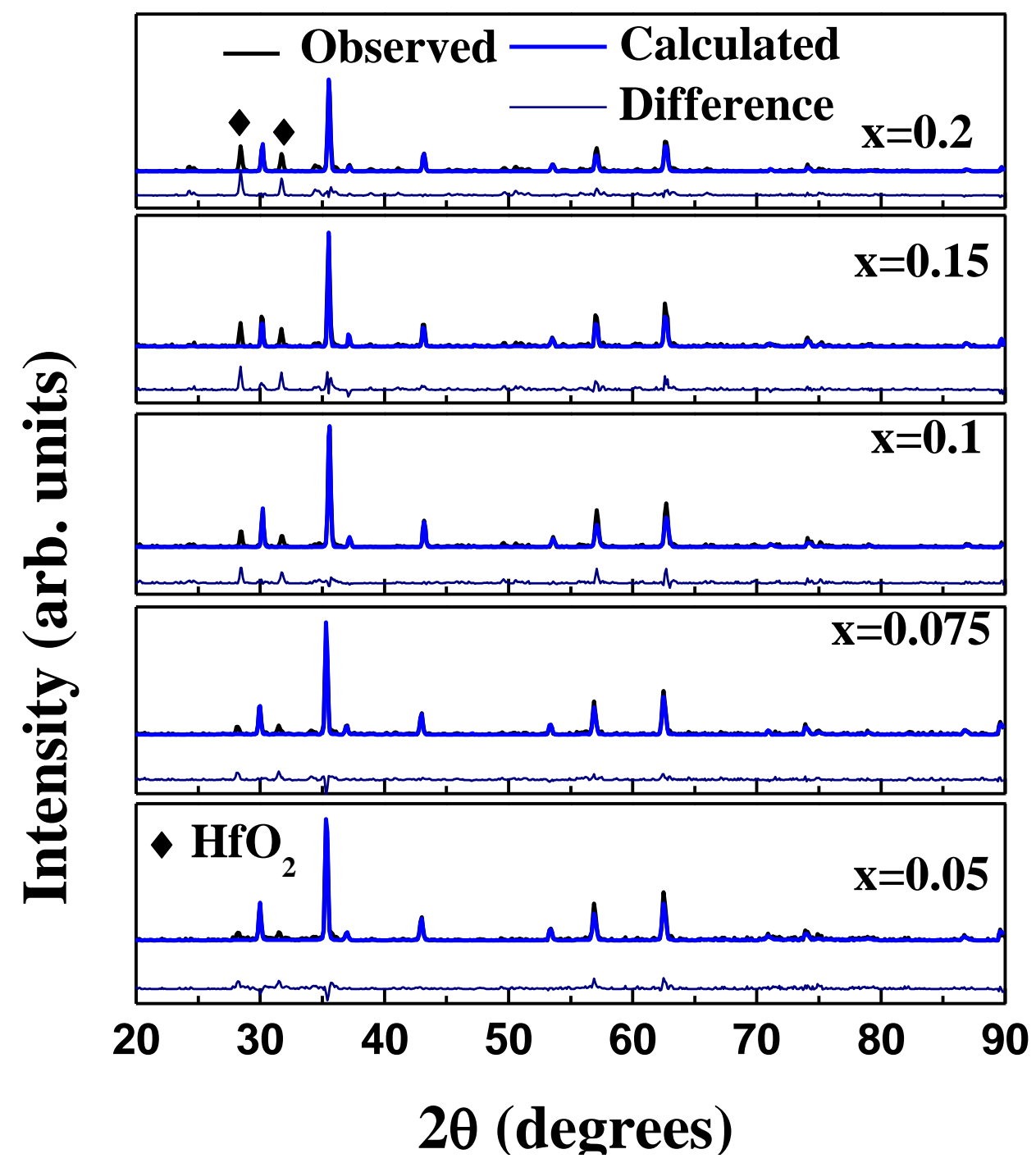

Fig. 3.4 XRD patterns for $\mathrm{CoFe}_{2-\mathrm{x}} \mathrm{Hf}_{\mathrm{x}} \mathrm{O}_{4}$

The lattice parameters of the composites can be obtained from these XRD curves. As the concentration of $\mathrm{HfO}_{2}$ increases, so does the lattice size. The lattice parameters increased from $8.374 \AA$ to $8.391 \AA$ with concentration increases of $\mathrm{Hf}$ in $\mathrm{CoFe}_{2-\mathrm{x}} \mathrm{Hf}_{\mathrm{x}} \mathrm{O}_{4}(\mathrm{x}=0.00,0.05,0.075,0.10,0.15$ and 0.20$)$. Even a small amount of $\mathrm{Hf}$ had a drastic effect on the lattice, the greatest jump in size being from pure $\mathrm{CoFe}_{2} \mathrm{O}_{4}$ to the $x=0.05$ concentration. The lattice constant determined for $x=0.05$ is $8.384 \AA$, a significant size increase from the $8.374 \AA$ of $\mathrm{CoFe}_{2} \mathrm{O}_{4}$ without $\mathrm{Hf}$. The ion $\mathrm{Hf}^{4+}$ is very large compared to $\mathrm{Fe}^{3+}(0.83 \AA$ compared to $0.67 \AA$ ). This greatly distorts the lattice upon incorporation of the Hf to Fe sites. This 
distortion can also be seen in the changes in Fe-O-Fe, Hf-O-Fe, Hf-O-Co bond angles and lengths at the $\mathrm{B}$ site [36,37]. Table 1 below summarizes the angle changes in the $\mathrm{x}=0.05$ concentration, and Figure 3.5 shows the lattice constant changes.

Table 1 Comparison of refined values of bond angle and bond length in pure $\mathrm{CoFe}_{2} \mathrm{O}_{4}$ and $\mathrm{CoFe}_{1.95} \mathrm{Hf}_{0.05} \mathrm{O}_{4}$.

\begin{tabular}{cccc}
\hline Compound & $\begin{array}{c}\mathrm{Fe}^{3+}-\mathrm{O}-\mathrm{Fe}^{3+} \\
\left(\mathrm{Hf}^{4+}\right) \text { Bond angle } \\
\text { (degrees) }\end{array}$ & $\begin{array}{c}\mathrm{Co}^{2+}-\mathrm{O}-\mathrm{Co}^{2+} \\
\text { Bond angle } \\
\text { (degrees) }\end{array}$ & $\begin{array}{c}\mathrm{O}-\mathrm{Fe}^{3+} \\
\left(\mathrm{Hf}^{3+}\right) \\
\text { Bond length } \\
(\AA)\end{array}$ \\
\hline $\mathrm{Co.Fe}_{2} \mathrm{O}_{4}{ }^{1}$ & 159.2 & 90.6 & 2.050 \\
$\mathrm{Co.} \mathrm{Fe}_{1.95} \mathrm{Hf}_{0.05} \mathrm{O}_{4}$ & 157.2 & 90.1 & 2.184
\end{tabular}

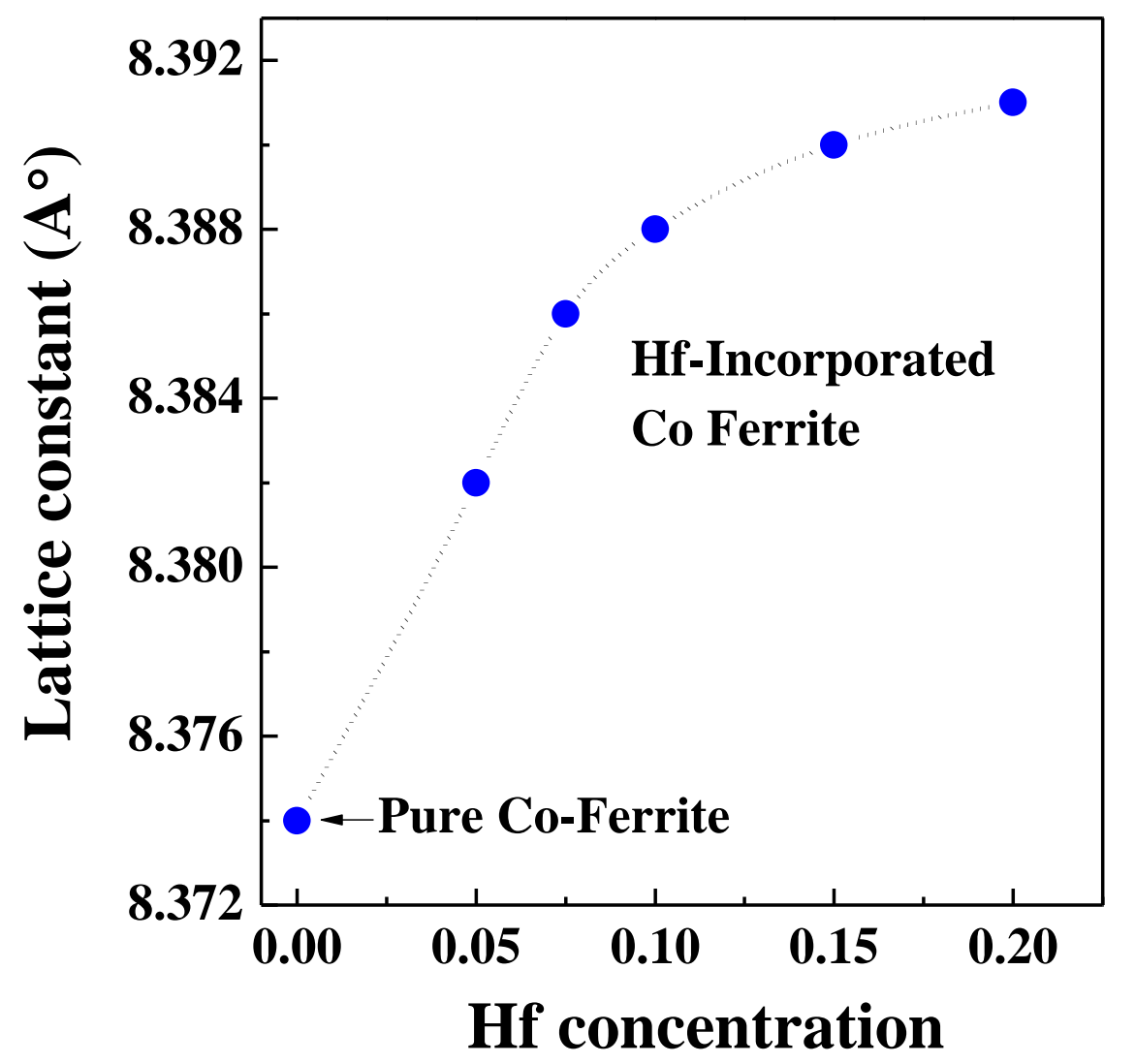

Fig 3.6 Concentration of $\mathrm{Hf}$ vs Lattice constant in $\mathrm{CoFe}_{2-\mathrm{x}} \mathrm{Hf}_{\mathrm{x}} \mathrm{O}_{4}$ 


\subsection{MORPHOLOGY AND COMPOSITION}

The SEM images from the different samples are shown below in Figure 3.7. The crystallites are seen to be evenly distributed in the scan. Also, smooth grain boundaries are evident.
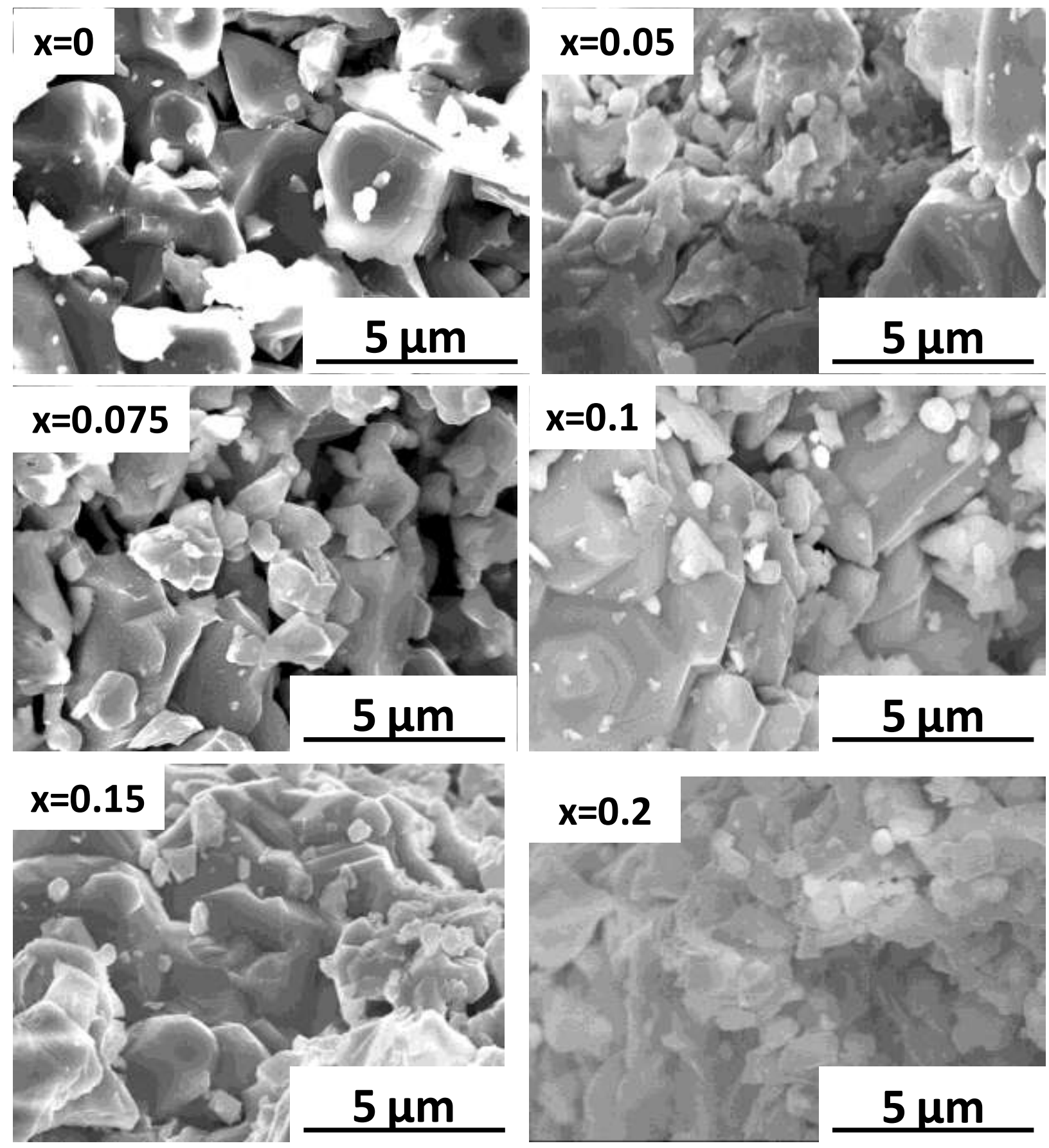

Fig 3.7 SEM images of $\mathrm{CoFe}_{2-\mathrm{x}} \mathrm{Hf}_{\mathrm{x}} \mathrm{O}_{4}$ 
The EDS scans show a qualitative balance of the elements in the samples based on the x-rays emitted by each ion when struck by an electron beam, which is unique to the generating element $[33,38]$. The scans are shown in the figure below as a function of Hf concentration.

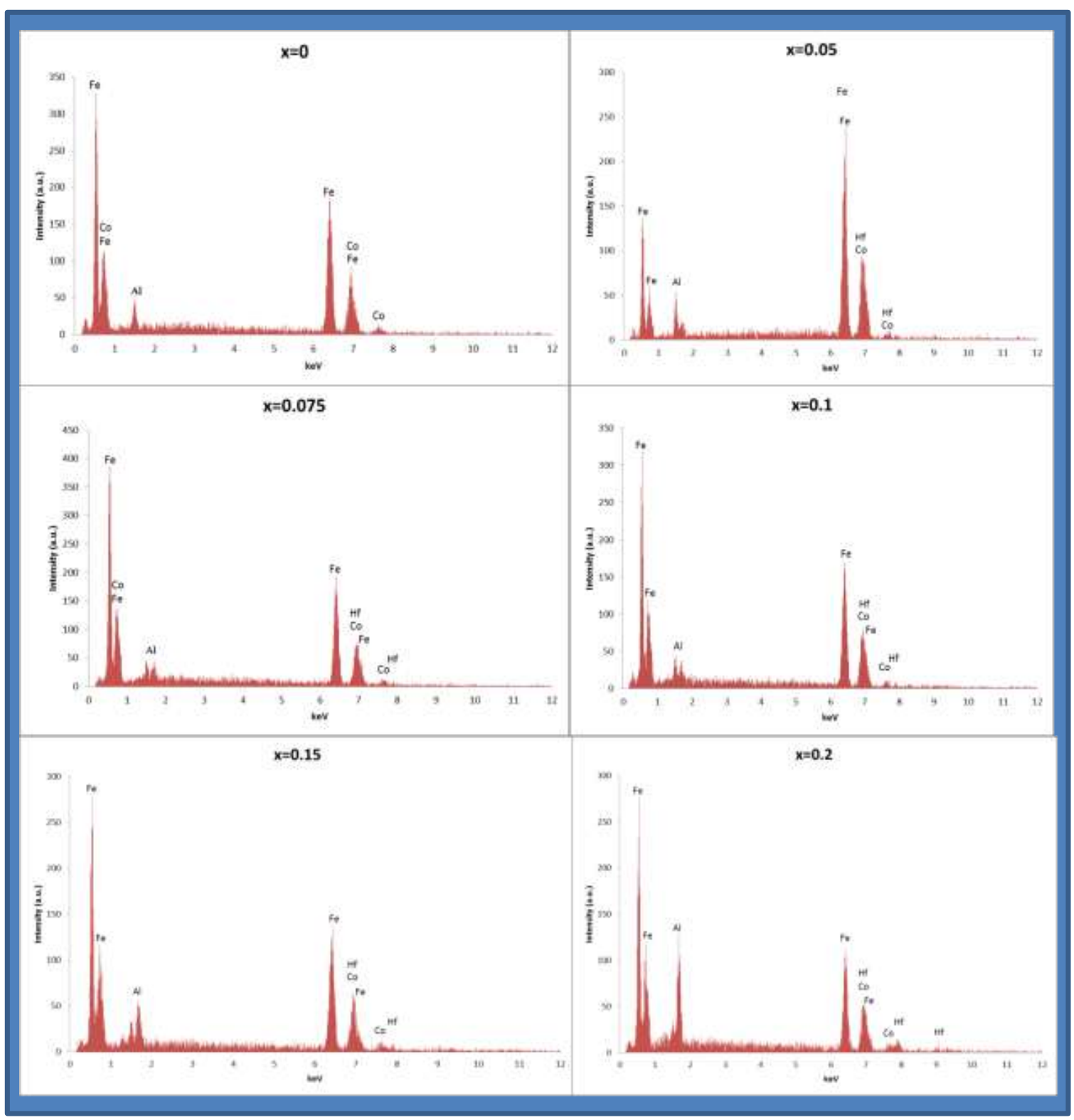

Fig 3.8 EDS of $\mathrm{CoFe}_{2-\mathrm{x}} \mathrm{Hf}_{\mathrm{x}} \mathrm{O}_{4}$

The materials are stoichiometric and homogeneous, being evenly distributed. The X-ray lines for Fe $\mathrm{K} \alpha$, $\mathrm{Co} \mathrm{K} \alpha, \mathrm{O} \mathrm{K} \alpha, \mathrm{La} \mathrm{L} \alpha$ and $\mathrm{Co} \mathrm{L} \alpha$ appear on the graph at their proper energy positions. Since there is no 
La in the sample, these are all for Fe, Co, Hf, and $\mathrm{O}$. C and $\mathrm{Al}$ also appear due to the carbon tape and $\mathrm{Al}$ holder used in the scan. The scan shows great purity in the samples, and proper increase in concentration of Hf in the high concentration samples.

\subsection{Dielectric Properties}

The change in the real part of the dielectric constant $\varepsilon$ ' was measured and plotted for the different concentrations of $\mathrm{HfO}_{2}$. Two trends become evident. First, the dielectric constant drops with increasing frequency, which is normal for spinel ferrites as well as for many other materials. Second, the dielectric constant and the stability of the constant with changing frequency both increase with increasing $\mathrm{HfO}_{2}$.

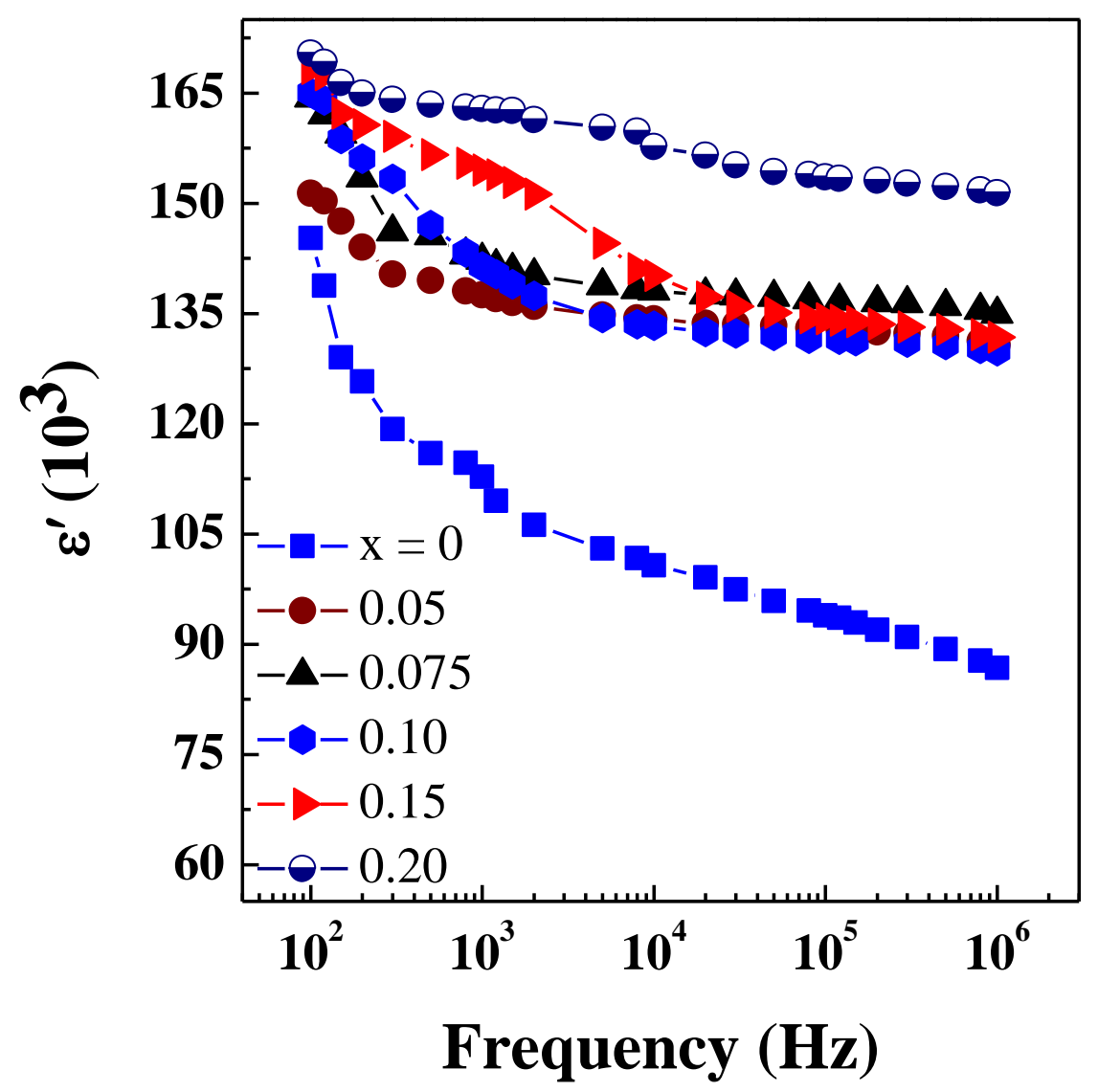

Fig 3.9 Real Portion of Dielectric Constant vs Frequency 
The increase the real dielectric constant with increasing Hf concentration is likely due to increasing $\mathrm{Fe}(\mathrm{Hf})-\mathrm{O}$ bond lengths at the $\mathrm{B}$ site with increasing lattice distortion. This creates stronger dipoles in the material. Also, $\mathrm{HfO}_{2}$ accumulating at grain boundaries creates greater interfacial polarization. A lag in the dipole behind the applied electric field causes the lowering of $\varepsilon^{\prime}$ at high frequencies. The loss of $\varepsilon^{\prime}$ at high frequencies is due to the loss of ionic and orientation polarizability. The other contributing factors such as interfacial and grain-boundaries still remain at high frequencies.

When looking at the curves formed by $\varepsilon^{\prime}$ vs frequency, it is useful to model the data. $\mathrm{O}^{2-}, \mathrm{Hf}^{4+}$ and $\mathrm{Fe}^{3+}$ all contribute to the relaxation process. When multiple ions contribute as such, a modified Debye's function is often used [37]. The function is as follows [39]:

$$
\varepsilon^{\prime}-\varepsilon_{\infty}=\frac{\left(\varepsilon_{0}-\varepsilon_{\infty}\right)}{\left[1+(\omega \tau)^{2(1-\alpha)}\right]}
$$

This proved a good fit, indicating that multiple ions do contribute to relaxation. Here, $\varepsilon^{\prime}$ is the real part of the dielectric constant, $\varepsilon_{\infty}$ is the dielectric constant at $1 \mathrm{MHz}, \tau$ is the mean relaxation time, $\alpha$ is the spreading factor of the actual relaxation times about the mean value, and $\omega$ is angular frequency. This model can be used to analyze relaxation times. The times are plotted against concentration of $\mathrm{HfO}_{2}$ in figure 3.10 . 


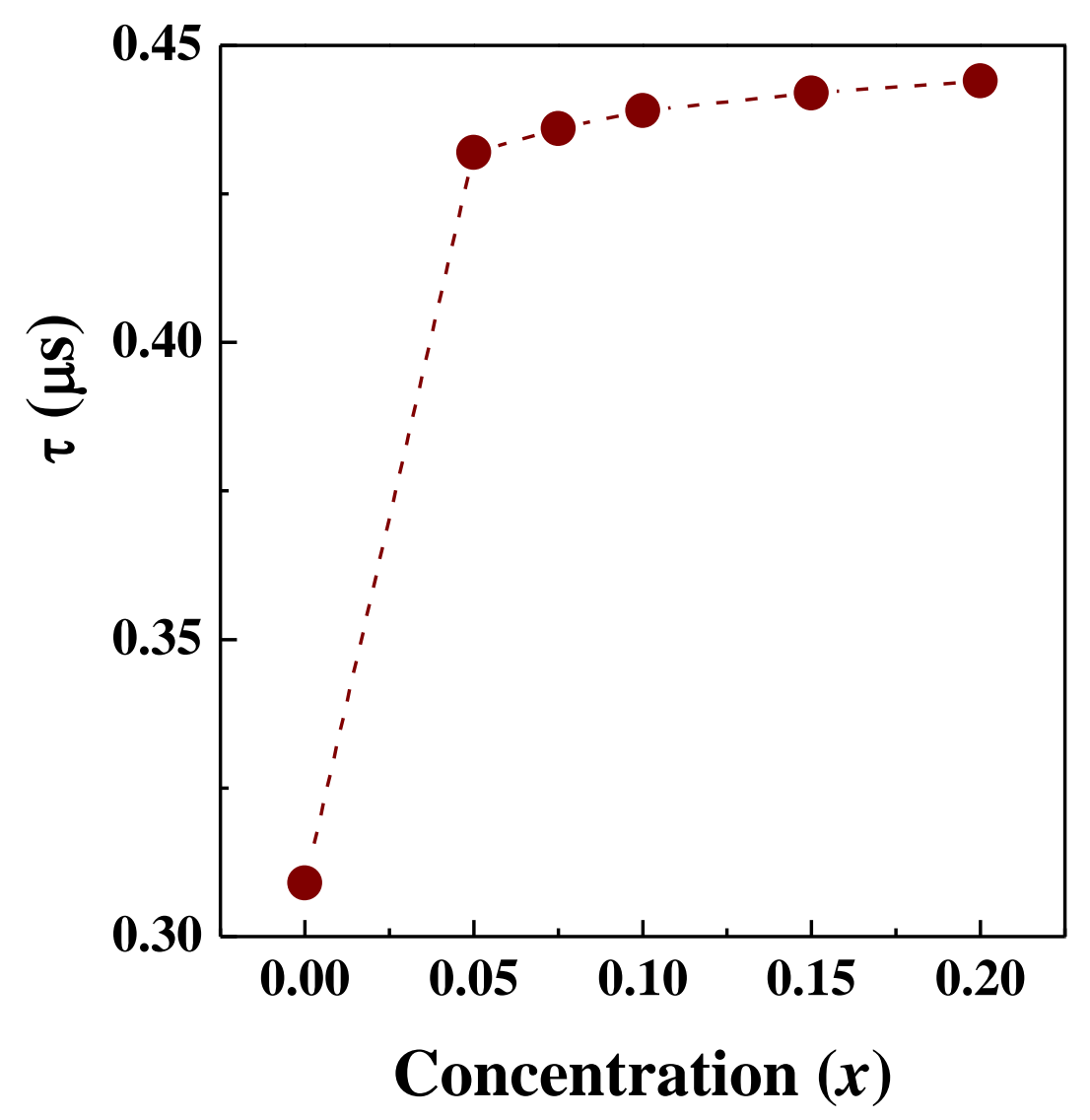

Fig 3.10 Relaxation Time vs Concentration of $\mathrm{HfO}_{2}$

A mean relaxation time of $\tau=0.309 \mu$ s and a spreading factor $\alpha=0.43$ were calculated for pure $\mathrm{CoFe}_{2} \mathrm{O}_{4}$. The relaxation time and spreading factor both jump greatly for any inclusion of $\mathrm{Hf}$. Concentrations of $\mathrm{x}=0.05$ to $\mathrm{x}=0.2$ in $\mathrm{CoFe}_{2-\mathrm{x}} \mathrm{Hf}_{\mathrm{x}} \mathrm{O}_{4}$ yield relation times from $0.432 \mu \mathrm{s}$ and $0.444 \mu \mathrm{s}$, and spreading factors from 0.59 to 0.68 . The lattice constant for the structure and the bond lengths increase for any Hf incorporation. This increases the inter-ionic distances and the jumping distance for the ions when the dipole switches. This increases the mean relaxation time and spreading factor. This trend is seen in other rare-earth ion doped Co- or Ni-based ferrites, such as with La, Dy, and Gd doping [40-43]. 


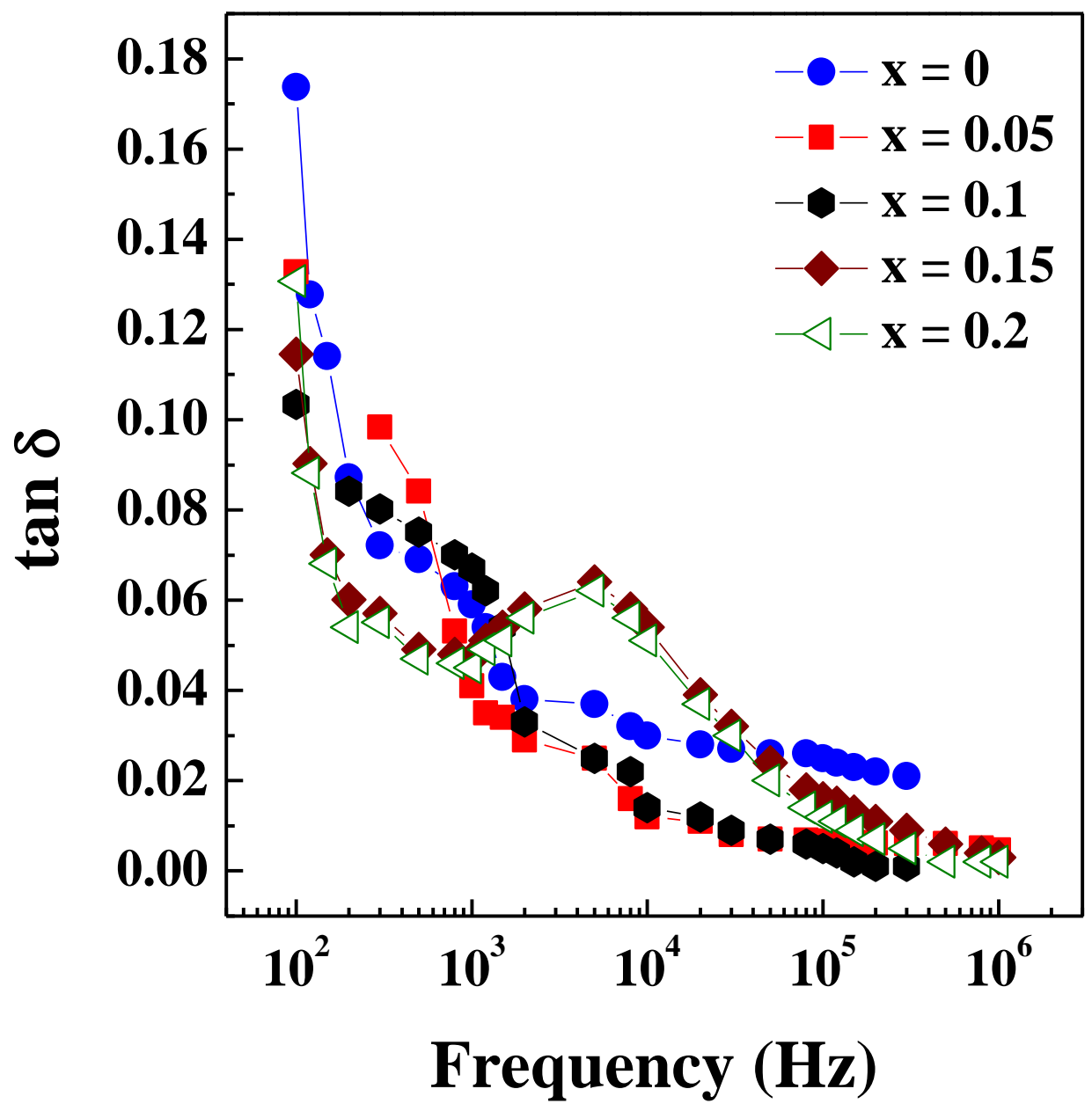

Fig 3.11 Frequency variation of $\tan \delta$ for $\mathrm{CoFe}_{2-\mathrm{x}} \mathrm{Hf}_{\mathrm{x}} \mathrm{O}_{4}$

The frequency variation of $\tan \delta$ is shown in Figure 3.11. The dielectric loss factor decreases with frequency as a general trend. A resonance peak occurs at $800 \mathrm{~Hz}$ for pure Co ferrite when the jumping frequency of the ions and the $\mathrm{AC}$ frequency are equal. The resonance peak occurs at a higher frequency with increasing $\mathrm{Hf}$ concentration, going to $5 \mathrm{kHz}$ for the higher concentrations. Dielectric loss is caused when the dipole lags behind the applied electric field and is increased by the impurity phase of 
$\mathrm{HfO}_{2}$. These samples have good homogeneity, so they have less of a loss from the $\mathrm{HfO}_{2}$. The synthesis process affects the homogeneity, and hence, the $\tan \delta$. 


\section{Chapter 4: Conclusions and Summary}

This work examined the microstructure and dielectric properties of the novel substitutional ferrite $\mathrm{CoFe}_{2-\mathrm{x}} \mathrm{Hf}_{\mathrm{x}} \mathrm{O}_{4}$. Samples of various concentrations were synthesized into both powders and tablets. X-ray crystal diffraction was used to determine the morphology and phase of the samples, showing that they crystalize in the inverse spinel phase, like CFO. Impurity phase of $\mathrm{HfO}_{2}$ occurs at higher concentration. SEM and EDS scans were taken of the powder samples. These scans showed both purity of the samples and homogeneity. The homogeneity is due to good sintering techniques. Dielectric spectroscopy was used to measure the dielectric properties of the material. The dielectric constant was measured against frequency for all concentrations. While the constant drops for high frequencies, it increases for higher $\mathrm{Hf}$ concentration and the loss of $\varepsilon$ ' at high frequencies can be significantly decreased at the higher $\mathrm{Hf}$ concentrations. By modeling the $\varepsilon^{\prime}$ curves to a modified Debye function, the relaxation time was calculated for the different samples. It was found that, due to increased hopping distance, the relaxation time goes up with addition of Hf, with a large initial jump for initial inclusion of Hf. The dielectric loss factor $(\tan (\delta))$ was found to decrease with increasing frequency, with a resonance peak at the point where frequency of the applied AC electric field matches the jumping frequency of the ions. This shifts to a higher frequency with increased concentration of Hf. The Hf concentration also affects $\tan (\delta)$ at different frequencies.

The study performed here has shed light on the effects of heavy ion substation into ferrites. It is the start of the examination Hf substitution, and has added to the general base of knowledge about heavy ion incorporated ferrites. The data yielded by the study shows excellent dielectric properties for properly sintered Hf-CFO. While the economic viability of this new material will become manifest in time as its benefits are weighed against the high cost of the Hf element, the science of ferrites has advanced another great step toward a full understanding of these materials. 


\section{Chapter 5: Future Work}

As this thesis work draws to a close, the work on Hf-CFO continues. As this is being written, data is being gathered for the temperature variance of the dielectric values made in this study. Work will continue, hopefully producing data on magnetic and mechanical properties in the future. Application of the new material as a thin film coating is also being examined by researchers here at the University of Texas at El Paso. 


\section{References}

1. [J. L. Snoek, Magnetic and electrical properties of the binary systems MO. $\mathrm{Fe}_{2} \mathrm{O}_{3}$ Physica (Holland), 3, 463-83 (1936).

2. J. L. Snoek, New Development in Ferromagnetic Materials. Elsevier, New York, 1947.

3. Mitsuo Sugimoto, The past, Present and Future of Ferrites, J. Am. Ceram. Soc., 82 [2] 269-80 (1999).

4. Bragg W. H., The Structure of Magnetite and the Spinels, Nature, 95,561(1915).

5. UmitOzgur, YahyaAlivov, HadisMorkoc; Microwave Ferrites, Part 1: Fundamental Properties, J Mater Sci: Mater Electron., 20:789-834 (2009).

6. Raul Valenzuela, Novel Applications of Ferrites, Physics Research International, Volume 2012, Article ID 591839

7. Biao Zhou, Ya-Wen Zhang, Chun-Sheng Liao, Chun-Hua Yan;Magnetism and Phase Transition for $\mathrm{CoFe}_{2-\mathrm{x}} \mathrm{Mn}_{\mathrm{x}} \mathrm{O}_{4}$ Nanocrystalline Thin Films and Powders, J. of Mag. and Mag. Mats. 247, 70-76, (2002).

8. A. Goldman, Modern Ferrite Technology, $2^{\text {nd }}$ Edition (Springer, New York, 2006).

9. T. Dhakal, D. Mukherjee, R. Hyde, P. Mukherjee, M. H. Phan, H. Srikanth, and S. Witanachchi; Magnetic Anisotropy and Field Switching in Cobalt Ferrite Thin Films Deposited by Pulsed Laser Ablation, J. Appl. Phys. 107, 053914 (2010).

10. Kamal KhajaMohaideen and Pattayil Alias Joy;Enhancement in the Magnetostriction of Sintered Cobalt Ferrite by Making Self-Composites from Nanocrystalline and Bulk Powders, ACS Appl. Mater. Interfaces, 4, 6421-6425 (2012).

11. C. N. Chinnasamy, B. Jeyadevan, K. Shinoda, and K. Tohji, D. J. Djayaprawira and M. Takahashi, R. Justin Joseyphus and A. Narayanasamy; Unusually High Coercivity and Critical Single-Domain Size of Nearly Monodispersed $\mathrm{CoFe}_{2} \mathrm{O}_{4}$ Nanoparticles, Appl. Phys. Lett., Vol. 83, No. 14, 6 (2003). 
12. R. M. Bozorth, E. F. Tilden, and A. J. Williums; Anisotropy and Magnetostriction of Some Ferrites, Phys. Rev. 99, 1788 (1955).

13. K. Maaza, ArifMumtaza, S.K. Hasanaina, Abdullah Ceylan; Synthesis and Magnetic Properties of Cobalt Ferrite $\left(\mathrm{CoFe}_{2} \mathrm{O}_{4}\right)$ Nanoparticles Prepared by Wet Chemical Route, J. of Mag. and Mag. Mats., 308, 289-295 (2007).

14. B. H. Liu and J. Ding; Strain-Induced High Coercivity in $\mathrm{CoFe}_{2} \mathrm{O}_{4}$ Powders, Appl. Phys. Lett. 88, 042506 (2006).

15. K. Maaz, M. Usman, S. Karim, A. Mumtaz, S. K. Hasanain, and M. F. Bertino; Magnetic Response Of Core-Shell Cobalt Ferrite Nanoparticles At Low Temperature,J. Appl. Phys. 105, 113917 (2009).

16. G. Hu, J. H. Choi, C. B. Eom, V. G. Harris, and Y. Suzuki; Structural Tuning of The Magnetic Behavior in Spinel-Structure Ferrite Thin Films,Phy. Rev. B, 62 (2), R779 (2000).

17. R. C. Kambale, P. A. Shaikh, C. H. Bhosale, K. Y. Rajpure and Y. D. Kolekar;The Effect of Mn Substitution on the Magnetic and Dielectric Properties of Cobalt Ferrite Synthesized by an Autocombustion Route, Smart Mater. Struct. 18, 115028 (2009).

18. Polder D.; "Ferrite Materials" Proceedings of the Institute of Electrical Engineers, Vol. 97, Part II, $246(1950)$.

19. M. Noor-A-Alam, C. V. Ramana, Synthesis and microstructure of $\mathrm{Gd}_{2} \mathrm{O}_{3}$-doped $\mathrm{HfO}_{2}$ ceramics, Ceram. Int. 38 (2012) 1801-1806.

20. M. Noor-A-Alam, C. V. Ramana, Structure and thermal conductivity of yttria-stabilized hafnia ceramic coatings grown on nickel-based alloy, Ceram. Int. 38 (2012) 2957-2961.

21. J. Robertson, High dielectric constant gate oxides for metal oxide Si transistors, Rep. Prog. Phys. 69 (2006) 327-396. 
22. G.D. Wilk, R.M. Wallace, J.M. Anthony, High-к gate dielectrics: Current status and materials properties considerations, J. Appl. Phys. 89 (2001) 5243-5243-33.

23. C.V. Ramana, K. Kamala Bharathi, A. Garcia, A.L. Campbell, Growth behavior, lattice expansion, strain and surface morphology of nanocrystalline, monoclinic $\mathrm{HfO}_{2}$ thin films, J. Phys. Chem. C 116 (2012) 9955-9960.

24. Sharon Mitchell and Javier Pérez-Ramírez. X-ray diffraction.Institute for Chemical and Bioengineering, ETH Zürich, Switzerland. Accessed on May 2013. http://cc.usst.edu.cn/Download/26da9cdf-6134-41fc-bf56-6dcccd9edd20.pdf

25. Paul Barnes, Tony Csoka, and Simon Jacques. 2006. Brag's Law. Birkbeck College, University of London. http://pd.chem.ucl.ac.uk/pdnn/powintro/braggs.htm

26. Susan Swapp, 2013, Scanning Electron Microscopy (SEM), Accessed June $25^{\text {th }}$, http://serc.carleton.edu/research_education/geochemsheets/techniques/SEM.html

27. Purdue University. 2010. Scanning Electron Microscope. Accessed May 2013. http://www.purdue.edu/rem/rs/sem.htm

28. Hafner, Bob. Energy Dispersive Spectroscopy on the SEM: A Primer. University of MinnesotaTwin Cities. Accessed May 2013. http://www.charfac.umn.edu/instruments/eds_on_sem_primer.pdf

29. Young, Hugh D. and Freedman, Rodger A.. 2008. University Physics. San Fransisco: Pearson Addison-Wesley

30. J. F. Becker, 2009, Capacitors, Accessed July $9^{\text {th }} 2013$, http://www.physics.sjsu.edu/becker/physics51/capacitors.htm 
31. Zhu, Chunxiang. Dielectric loss. Accessed on July $9^{\text {th }} 2013$. http://faculty.kfupm.edu.sa/EE/zhamouz/051/EE620-051/others/2_Dielectric_loss.pdf

32. Eduard Cartier, Jerry Chen, Chao Zhao, 2008, Transistors or memory capacitors comprising a composition of HfO2 with enhanced dielectric constant, Accessed on July $9^{\text {th }} 2013$, http://www.google.com/patents/EP1372160B1?cl=en

33. C. V. Ramana, A. Ait-Salah, S. Utsunomiya, J. F. Morhange, A. Maugher, F. Gendron, C. M. Julien, Spectroscopic and chemical imaging analysis of Lithium Iron triphosphate, J. Phys. Chem. C 111 (2007) 1049-1054.

34. Robert John Lancashire, 2000, An Inverse Spinel $-\mathrm{NiFe}_{2} \mathrm{O}_{4}$, Accessed July $9^{\text {th }} 2013$, http://wwwchem.uwimona.edu.jm/courses/invspinelJ.html

35. S. Wells, C. V. Ramana, Hafnium Oxide - Cobalt Ferrite Composite for use in High Energy Density Capacitors,Minority Leaders Review Program (2001)

36. S. Chikazumi, Physics of Ferromagnetism (Oxford University Press, New York, 1997).

37. J. Smith and H. P. J. Wijn, Ferrites, Philips Technical Library, Eindhoven Holland, 1965.

38. C V. Ramana, A. Ait-Salah, S. Utsunomiya, U. Becker, A. Mauger, F. Gendron, C. M. Julien, Structural characteristics of Nickel phospahtes studied using analytical electron microscopy and Raman spectroscopy, Chem. Mater. 18 (2006) 3788-3794.

39. R.C. Che, C. Y. Zhi, C. Y. Liang, X. G. Zhou, Fabrication and microwave absorpotion of carbon nanotubes/CoFe $\mathrm{O}_{4}$ spinel nanocomposite, Appl. Phys. Lett. 88 (2006) 033105-1 - 033105-3.

40. K. Kamala Bharathi, G. Markendeyulu, C. V. Ramana, Enhanced dielectric property of Ni ferrite by Sm and Ho substitution,Electrochem. Solid-State Lett. 13 (2010) G98-G102. 
41. N. Rezlescu, E. Rezlescu, C. Pasnicu, M. L. Craus, Effects of the rare-earth ions on some properties of nickel-zinc ferrite,J. Phys.: Condens. Matter.6(1994) 5707-5716.

42. K. Kamala Bharathi, C.V. Ramana, Improved dielectric properties La-doped Co ferrite, J. Mater. Res. 26 (2011) 584-591.

43. R. S. Devan, Y. D. Kolekar, B. K. Chougule, Effect of cobalt substitution on the properties of nickelcopper ferrite, J. Phys.: Condens. Matter.18 (2006) 9809-9822. 


\section{Vita}

The author was born in Kingsville, TX and spent most of his childhood in El Paso, TX. After living overseas in Bolivia, and spending his high school years in Florida, he returned to El Paso where he graduated Magna Cum Laud with a B.S. in mechanical engineering from UTEP. During that time the author interned at the Boeing corporation and worked on the 787 project, and became a member of Pi Tau Sigma. Most of his time as an undergraduate, he worked as a tutor with UTEP's Academic Center for Engineers and Scientists. His research in his master's is summarized in this thesis, and has been

presented in the Minority Leader Review Program in 2011, and the $2^{\text {nd }}$ South West Energy Symposium in 2012 .

Permanent address: 6531 La CadenaDr

El Paso, TX 79912

This thesis was typed by Stephen Wells. 